\title{
Lejos, tranquilos y solos. Experiencias espaciales en el partido de general Pueyrredon (Buenos Aires, Argentina)
}

Sofía Ares ${ }^{1}$

Tipo de trabajo: Artículo

Material original autorizado para su primera publicación en la Revista Académica de la Facultad de Ciencias Sociales de la Universidad de Palermo.

Recibido: 8-9-2012

Aceptado: 12-12-2012

\section{Resumen}

El área de estudio está concentrada en Chapadmalal y se extiende por el eje costero sur del distrito de General Pueyrredon (Buenos Aires, Argentina), llegando a las ciudades de Mar del Plata y Miramar (General Alvarado). El objetivo es comprender los significados del espacio vivido y las tramas de sentido construidas por los sujetos acerca de Chapadmalal y las áreas recorridas habitualmente. La propuesta, referida a los espacios vividos en un ámbito como Chapadmalal, es una contribución original destinada a la ampliación de los conocimientos vinculados con la vida cotidiana y la subjetividad espacial. Para abordar el problema se realizaron cinco entrevistas en profundidad centradas en tres ejes temáticos que permitieron a los sujetos narrar sus prácticas espaciales y vivencias. El entramado reconstruido muestra los significados (lugar alejado, lugar ideal, lugar social, lugar de pertenencia) que dan forma al espacio vivido, producidos por los distintos modos de leer al espacio. La identificación de sentidos presupone un análisis minucioso de las narrativas, deconstruyéndolas para luego reconstruir la trama que los sujetos ponen en juego cuando reconocen a un lugar como propio, semantizándolo y usándolo de acuerdo con necesidades, contingencias y subjetividades. Aunque se reconoce que las tramas de sentido son dinámicas y cambiantes, se destaca el valor de este tipo de indagaciones para la comprensión de los procesos de territorialización, así como la consideración de la subjetividad espacial en la gestión territorial.

Palabras clave: espacio vivido, experiencia espacial, tramas de sentido, localidades menores

\footnotetext{
${ }^{1}$ Licenciada en Geografía (UNMdP) y Magíster en Ciencias Sociales y Humanidades (UNQ). Integra el Grupo de Estudios sobre Población y Territorio (UNMdP) y fue becaria de investigación en esa universidad de 2005 a 2012.

E-mail: ares.sofi@gmail.com
} 


\section{FAR, QUIET AND ALONE. SPATIAL EXPERIENCES IN GENERAL PUEYRREDON (BUENOS AIRES, ARGENTINA)}

\section{Abstract}

The study area is Chapadmalal, located in the south coastal axis of General Pueyrredon Municipality (Buenos Aires, Argentina). The aim of this article is to understand the meanings of lived space and the patterns of meaning constructed by the subjects about Chapadmalal and the areas where they frequently travel.

The in-depth interview allowed that the subjects narrate their spatial practices and experiences. The intention was that it be possible to recognize and interpret the given senses at the lived space in the narrations. The reconstructed plot shows the meanings that shape the lived space. It is produced by different ways of reading the space through the experience, ways of thinking, desires, fears, in relation to where people travel and especially where people is settled. This study contributes to understand territorial process and also the spatial subjectivity in the territorial management.

Keywords: lived space, spatial experience, plot of sense, small towns

\section{Introducción}

En la actualidad, son cada vez más numerosas las investigaciones geográficas que estudian la construcción del territorio desde la perspectiva de los sujetos (Hiernaux y Lindón, 2011). Así, además de la estructura económica y las relaciones sociales, se focaliza en la subjetividad espacial a través de los sentidos, los sentimientos y emociones, los lazos afectivos que hacen del territorio un espacio vivido o lugar².

En este sentido, a lo largo del trabajo se expondrá sobre la subjetividad de los habitantes de Chapadmalal y su articulación con aspectos materiales del territorio. El interés por esta vinculación surgió en el transcurso de trabajos de investigación en pequeñas localidades ${ }^{3}$, porque en estas primeras aproximaciones se observaron porciones de una realidad socioespacial que es opacada por Mar del Plata, cabecera del partido de General Pueyrredon (provincia de Buenos Aires). Por tanto, indagar en el poblamiento, los aspectos socio-demográficos, la calidad de vida y la movilidad diaria fueron puntos de partida para la elaboración de discusiones sobre las formas de construir el territorio.

Es importante remarcar que el poblamiento contemporáneo de los lugares más distantes de Mar del Plata se manifiesta sobre todo desde los años ochenta del siglo pasado (Nuñez, 2000; Lucero, 2004a; Sagua, 2004; Ares, 2008). En general se trata de localidades que presentan diversas limitantes con respecto a la provisión de servicios públicos (redes de agua, cloacas y gas;

\footnotetext{
${ }^{2}$ Este artículo expone resultados de la tesis de Maestría en Ciencias Sociales y Humanidades, Universidad Nacional de Quilmes, aprobada el 24 de noviembre de 2011. La autora agradece los aportes de la Mag. Patricia Lucero y la Dra. María Eugenia Comerci en la realización de la tesis, así como las sugerencias y observaciones del jurado formado por la Dra. Cristina Carballo, el Dr. Ramiro Segura y la Dra. Inés Pérez.

${ }^{3}$ Estas localidades tienen menos de 5000 habitantes cada una. Calificarlas como pequeñas o menores se asocia con la cantidad de pobladores que tiene cada una de ellas. Para identificar a las localidades o centros poblados se adopta el criterio propuesto por el Instituto Nacional de Estadística y Censos (2001), entonces una localidad se define como concentración espacial de edificios conectados entre sí por calles. Además, otra condición, está dada por la separación superior a los 2 kilómetros respecto de otra aglomeración (Ares, Mikkelsen y Sabuda 2011).
} 
atención sanitaria; educación; transporte) y distancias superiores a diez kilómetros con relación a la aglomeración principal. Su elección como destino residencial se relaciona con particularidades del mercado inmobiliario -menor costo de los inmuebles- y características que para los sujetos brindan la posibilidad de mejorar la calidad de vida -espacios verdes, arboledas, playas, sierras y baja densidad de población- (Ares y Mikkelsen, 2010). De manera que en esta disyuntiva entre caracteres negativos y positivos de las localidades se encuentra el problema de investigación, observado desde los lazos entre los sujetos y el territorio.

En este trabajo se busca brindar respuestas a algunos de los siguientes interrogantes: ¿qué sentido tiene la localidad para cada sujeto, como lugar de residencia desde donde se organiza la vida cotidiana?, ¿cómo se relacionan los sujetos con los lugares? ¿qué sentidos le asignan a otras ciudades y localizaciones de tránsito y permanencia?.

El objetivo es comprender los significados del espacio vivido y las tramas de sentido construidas por los sujetos residentes en Chapadmalal, acerca de esta localidad y las áreas recorridas habitualmente.

El área de estudio está concentrada en Chapadmalal y se extiende sobre el eje costero sur de General Pueyrredon, hasta las ciudades de Mar del Plata y Miramar (Partido de General Alvarado). Esta delimitación no excluye alusiones a localidades ubicadas en otros partidos o provincias.

Respecto de la perspectiva teórica humanista, el estudio de los espacios vividos y la subjetividad espacial, en Argentina se encuentran trabajos que exhiben la relevancia de indagar en los lazos subjetivos con el territorio. Aunque los autores abordan diferentes problemas, en distintos ámbitos, la potencialidad del enfoque permite advertir, por ejemplo, cómo los inmigrantes bolivianos en Argentina construyen la territorialidad andina fundada en la relación cultura e identidad, mediante la recreación, en el Área Metropolitana de Buenos Aires, de territorios bolivianos (Sassone, 2002). Por otra parte, Gabriel Álvarez (2005), desarrolla su indagación en el Partido de General San Martín (Buenos Aires), enfocada desde los sujetos y la teoría del lugar y reconoce las maneras de apropiarse del espacio, las identidades y las consideraciones respecto del otro/ los otros y de las diferenciaciones territoriales dentro del barrio. Los resultados de su investigación muestran el tratamiento del espacio como un lugar, a la vez ideal y estructurado por macroprocesos. Finalmente, Eugenia Comerci (2010), en el extremo oeste pampeano identifica ciclos en el proceso de estructuración espacial que expresan condiciones materiales de producción-reproducción, así como sentidos y representaciones de los sujetos. Contrapone en su investigación el rol de los agentes foráneos que imponen tiempos, formas y sentidos, a la resistencia y espacialidad propia construida por los crianceros campesinos.

A partir de estos ejemplos se observa el estudio de las individualidades en el marco de grandes procesos sociales, económicos, políticos (Sassone, 2002; Álvarez, 2005; Comerci, 2010), constituyendo así un aporte integral al conocimiento geográfico.

La propuesta del artículo, referida a los espacios vividos en un ámbito como Chapadmalal, es una contribución original destinada a la ampliación de los conocimientos vinculados con la vida cotidiana y la subjetividad espacial. La argumentación se estructura en cuatro secciones. En la primera se describen algunas particularidades del área de estudio. En un segundo momento se abordan aspectos referidos a la teoría, el método y la técnica, exponiendo la articulación entre lo conceptual y su implementación. A continuación se despliegan los resultados, donde son centrales los significados del espacio vivido y las tramas de sentido. Para finalizar se propone una recapitulación de 
los resultados, donde se remarcará la importancia de este tipo de indagaciones para la comprensión de los procesos de territorialización y la relevancia de la subjetividad espacial en la gestión territorial.

\section{El área de estudio}

El Partido de General Pueyrredon ( $38^{\circ} 02^{\prime}$ latitud Sur y $57^{\circ} 39^{\prime}$ de longitud Oeste) cuenta con 618989 habitantes (INDEC $\left.{ }^{4}, 2010\right)$ y se ubica en el sudeste de la provincia de Buenos Aires, en el área denominada Pampa surera o interserrana (Ver Mapa 1). En el municipio sobresale su ciudad cabecera, Mar del Plata, que en el año 2001 tenía 524553 habitantes (INDEC, 2001).

Hasta los años ochenta del siglo XX el poblamiento del Partido de General Pueyrredon estuvo liderado por Mar del Plata, ciudad que tuvo tasas de crecimiento elevadas con protagonismo del componente migratorio. Pero el incremento anual de la población comenzó a reducirse entre los años setenta y ochenta (Lucero, 2004a), y se inició un período caracterizado por el acelerado ritmo de acrecentamiento poblacional en las pequeñas localidades. Entre 1980 y 1991, las aglomeraciones de la Autovía 2 registraron las mayores tasas de crecimiento anual intercensal (Sagua, 2004); mientras que entre 1991 y 2001 la expansión se orientó hacia la Ruta 11. Por ejemplo Chapadmalal, tuvo en el último período una tasa de crecimiento anual del 2.9 \% constituye uno de los destinos elegidos en el marco de procesos de movilidad territorial.

Esta localidad, se subdivide en cinco barrios (Playa Los Lobos, Estafeta Playa Chapadmalal, Santa Isabel, Arroyo Chapadmalal y San Eduardo de Chapadmalal). El examen de los datos de INDEC (1980, 1991 y 2001) permite reconocer el incremento poblacional del área demostrando que supera su tasa de crecimiento supera la del distrito en su conjunto.

El reconocimiento de algunas características socio-demográficas se relaciona con el proceso de construcción del territorio, con la fuerte impronta de constantes radicaciones más o menos recientes. En Chapadmalal son significativos los porcentajes de habitantes (60 al $70 \%$ ) que no cumplieron con la totalidad de los ciclos educativos primario y secundario, lo que repercute en su inserción laboral, predominante en servicios simples y en numerosos casos sin registrar. Predominan las viviendas de tipo $\mathrm{A}$, definidas por INDEC como las que cumplen con los requisitos de un hábitat seguro, privado y que resguardan a sus habitantes de las inclemencias meteorológicas. Los tipos de tenencia más frecuentes son "propiedad de la vivienda y el terreno" y "por trabajo".

Figura 1. Localización relativa del Partido de General Pueyrredon y Chapadmalal

4 INDEC: Instituto Nacional de Estadística y Censos de la República Argentina 


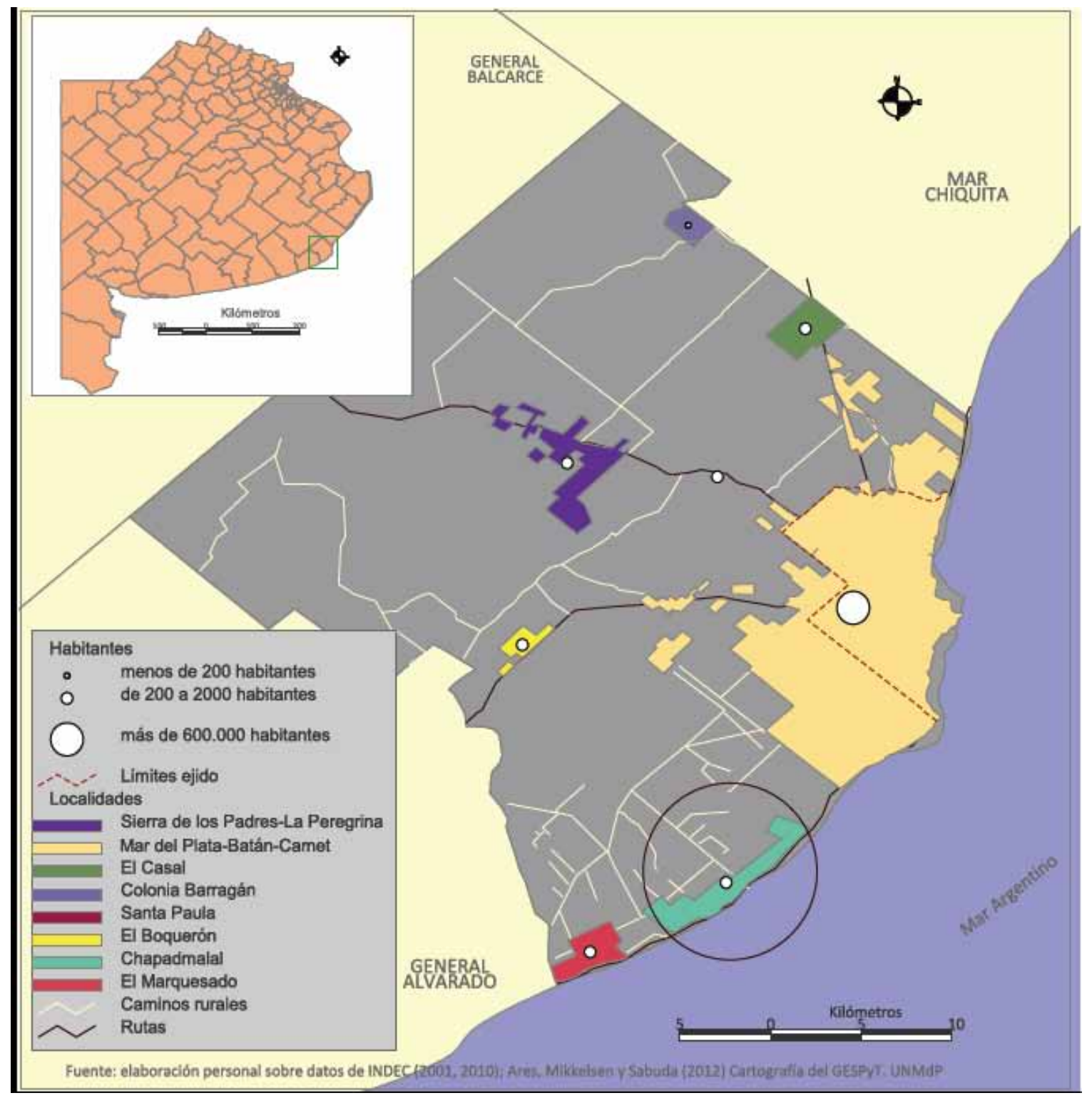

El crecimiento de Chapadmalal acontece en el marco de procesos en los que se revalorizan espacios antagónicos del Partido de General Pueyrredon. Por un lado hay una puesta en valor de las áreas más tradicionales de Mar del Plata-fomentando la renovación del Centro y algunos de sus barrios adyacentes-; por otro lado crecen las localidades en general y la periferia sur con la creación de urbanizaciones cerradas ${ }^{5}$. Tanto la expansión de localidades como la implantación de nuevas urbanizaciones, constituyen alternativas residenciales que ponen en tensión a lugares y personas con la llegada de nuevos habitantes, quienes portan prácticas socio-espaciales, sentidos, jerarquías y expectativas vinculados con su historia personal, su presente y sus proyectos.

En referencia a Chapadmalal, los procesos sobrevenidos en las últimas décadas del siglo XX y la primera del siglo XXI la ponen en escena como un lugar posible de ser habitado de forma estable, aunque no exento de problemas, relacionados con la falta de servicios públicos y la distancia respecto de Mar del Plata y Miramar (Partido de General Alvarado), ciudades con mayor oferta de actividades y servicios.

${ }_{5}^{5}$ Sobre la Av. Jorge Newbery se desarrollan en la actualidad los siguientes emprendimientos: Las Prunas, Arenas al Sur, Rumencó, Tierra y Mar. En Chapadmalal se encuentra el emprendimiento Barrancas de San Benito. 


\section{Una geografía desde los sujetos. El espacio vivido}

Frente a lo expresado, el enfoque elegido responde a la intención de hacer una geografía desde los sujetos, es decir, a partir de quienes habitan, utilizan y se apropian del espacio. Se sigue la perspectiva teórica de la Geografía Humanista, que focaliza en el espacio vivido o lugar. En esta investigación se entiende al espacio vivido como aquel que concentra cargas emotivas, imágenes y conceptos que forjan la representación del mundo y le dan sentido (Di Méo apud Lindón 2007a, p. 382). El espacio vivido expresa la relación subjetiva que el individuo socializado, solo o de manera colectiva, establece con la tierra y con sus lugares. Está impregnado de valores culturales y se lo conoce estudiando a los actores, sus prácticas y significaciones espaciales (Di Méo, 1999). En armonía con esta definición, el concepto de lugar "hace referencia a espacios delimitados, con límites precisos, que para los sujetos representan certezas y seguridades otorgadas por lo conocido" (Tuan apud Lindón et al. 2006, p. 13).

Interrogar al territorio (Haesbaert, 2004) desde la perspectiva de los habitantes es el camino para observar e interpretar sus espacios vividos, espacios con límites precisos pero flexibles, cargados de sentidos que los particularizan. Espacios que los sujetos viven como propios en distinto grado y (re) dibujan en el transcurrir de sus biografías al mismo tiempo que participan en la construcción social del territorio.

Los sujetos elegidos para la realización de entrevistas en profundidad surgen de una muestra tomada previamente (2007) conformada por treinta personas (veinte de sexo femenino) con una edad promedio de 45 años y una formación académica donde los niveles alcanzados predominantes son secundario incompleto y primario completo. La condición de ocupación, y las labores desarrolladas por estas personas muestran cierta vinculación con el escalafón educativo logrado. La mayor parte de los entrevistados son subocupados horarios y se desempeñan en labores simples como arreglo de parques y jardines, mantenimiento de viviendas, servicio doméstico en hoteles de la zona. La elevada proporción de inactivos es congruente con el envejecimiento que se detecta en la localidad (el $15 \%$ de los pobladores tenía más de 64 años en el año 2001).

\section{Un paso más, la articulación entre teoría y método}

El ingreso a la subjetividad espacial se realizó a través de los significados o sentidos y las tramas que estos constituyen, en tanto orientan las prácticas espaciales e inciden en la construcción del espacio vivido (Lindón, 2006, 2007b). Una aproximación sencilla al término sentido lo asimila a significación -la aceptada por convención y las distintas interpretaciones posibles-, y a sentimientos ${ }^{6}$.

Pero abordar los sentidos presupone internarse en caminos complejos y poco conocidos, donde los significados se entrelazan y conforman una trama que comprende nexos subjetivos, estos pueden ser estéticos, sensoriales (en especial táctiles), histórico-sociales o personales (Tuan, 2004). En esta última situación se manifiesta “... el sentir que uno tiene hacia un lugar porque es nuestro

\footnotetext{
${ }^{6}$ Según el diccionario de la Real Academia Española, las siguientes son acepciones del término sentido, que se ajustan al estudio geográfico propuesto: - Que incluye o expresa un sentimiento; - Modo particular de entender algo, o juicio que se hace de ello;- Significación cabal de una proposición o cláusula; - Cada una de las interpretaciones que puede admitir un escrito, cláusula o proposición.
} 
hogar, el asiento de nuestras memorias o el sitio donde nos ganamos la vida" (Tuan 2004: p. 130).

Las tradiciones teóricas que estudian el espacio y la espacialidad a través de los conceptos de espacio vivido o lugar reconocen el enlace entre componentes materiales y no materiales (Lindón, 2008). Los recintos de sentido son “...creados a partir de la reapropiación de ciertos elementos materiales -de manera situacional- y de su resignificación, sin que ello implique necesariamente modificaciones materiales" (Lindón, 2007b, p. 222). El espacio vivido no es un mero receptor o contenedor de significados, tiene un papel activo, con injerencia sobre estos y las acciones futuras. Es decir, el territorio es una construcción social, mediada por las normas y la subjetividad. Pero al mismo tiempo, el territorio construido resulta un condicionante de las acciones sociales y es partícipe de los procesos de formación de sentido.

En la vida cotidiana ${ }^{7}$ los sujetos elaboran su espacio vivido y en este proceso continuo se crean enlaces afectivos que pueden adquirir matices positivos o negativos. En consecuencia, el espacio vivido estará constituido por múltiples dimensiones, donde los significados brindados a los lugares y las relaciones de afecto o aversión configurarán formas de actuar y de espacializarse.

La cotidianeidad de las prácticas espaciales está asociada con este enfoque y con la construcción social de la realidad, donde el espacio "usado" (comillas) es otra instancia en interacción. Los sujetos residen en un territorio, donde son centrales las relaciones sociales porque a partir de ellas la cotidianeidad cobra un significado intersubjetivo. El sentido de los lugares se gesta en esas relaciones, se define socialmente. Tampoco son ajenos, a la asignación de significados, el tiempo pasado y la proyección que efectúa cada sujeto.

La vida cotidiana se presenta como una realidad objetiva, formada por un conjunto de objetos (Berger y Luckmann, 1968). Como componente de la cotidianeidad, el territorio también es una realidad objetiva, con subjetividades subyacentes que le dan sentido a las formas y configuraciones. En el territorio las intenciones subjetivas que dan origen a una forma pueden variar en el tiempo y entre sujetos. Una de las particularidades de la indagación geográfica es que se puede entender al propio espacio como un texto a ser interpretado, con lo cual el objetivo no es analizar los discursos de los sujetos per se, sino como formas de leer al territorio y a las prácticas sociales.

\section{De la teoría al campo}

La entrevista en profundidad (Scribano, 2008) permitió que los sujetos narraran sobre sus prácticas espaciales ${ }^{8}$ y vivencias, que pusieran en palabras vestigios de "sus mundos" (de Certeau, 2000) pasados y actuales. Se buscó que los sujetos hicieran un relato en el cual se reconocieran los sentidos asignados al espacio vivido. Bajo esta premisa se construyó un guión de entrevista organizado en tres ejes temáticos: a) Historia de movilidad territorial, b) Usos y significados del espacio, c) Relaciones sociales y de poder. Entre los meses de octubre y noviembre de 2010 se obtuvieron las cinco narrativas que exponen distintas lecturas sobre el territorio y los vínculos que los sujetos tienen con él.

${ }^{7}$ Se entiende al ámbito de la vida cotidiana como aquel construido por prácticas, lógicas, espacios y temporalidades repetidas, que aseguran la reproducción social (Reguillo 2000: pp. 77-78). Es en el cotidiano donde se elaboran vínculos sociales mediante la práctica de actividades y de desplazamientos con fuerte sustento espacial.

${ }^{8}$ Otras formas de conocer las prácticas espaciales y los significados del espacio vivido son las historias de vida y los mapas cognitivos, aunque en este último caso su puesta en práctica es discutida. Cfr. Constancio de Castro Aguirre, Mapas cognitivos. Qué son y cómo explorarlos. Scripta Nova. Revista Electrónica de Geografía y Ciencias Sociales. Universidad de Barcelona. № 33, 1 de febrero de 1999 
Por su protagonismo en la constitución de los campos de información espacial, los espacios de vida individuales (Ares, 2010) y algunas características socio-demográficas fueron el insumo básico para la selección de los cinco casos de entrevista. La muestra quedó conformada por dos hombres (39 y 48 años) y tres mujeres (40, 49 y 68 años). Se trata de cuatro personas que integran hogares con tres o más miembros y un sujeto que constituye un hogar unipersonal. Solo uno de los entrevistados tiene nivel secundario completo, los restantes cumplieron la escolaridad primaria. El ámbito laboral de estos pobladores está vinculado especialmente con el cuentapropismo informal (pintura, electricidad, construcción, arreglo de jardines, empleo doméstico). Todos los sujetos, al momento de ser contactados, tenían vehículo propio (auto o moto). Además, uno de los sujetos es nacido y criado en Chapadmalal, lo cual le otorga una visión y un sentir bastante disímil respecto de los restantes, quienes desarrollan un recorrido que muestra como la perspectiva idílica se va transformando a medida que transcurre el tiempo de radicación aunque sin perder de vista que dominan los sentidos positivos. Aunque la entrevista fue individual, también se obtuvieron datos referidos a la movilidad diaria de otros miembros del hogar y sobre todo se buscó conocer la forma de subsistencia del hogar para lo cual fue preciso indagar en el empleo de los distintos integrantes o las fuentes de obtención de ingresos.

\section{Las tramas del espacio vivido}

En la producción de significados tienen injerencia las características socio-demográficas y los campos de información espacial de cada individuo, aunados en el ámbito intersubjetivo.

Aunque algunos entrevistados tienen espacios de vida extensos y complejos, en gran medida su cotidianeidad se concreta en Chapadmalal, de ahí que la mayor parte de las referencias obtenidas son sobre este poblado y su área próxima. La subjetividad espacial se construye y reconstruye en la realización de prácticas, en los encuentros sociales y en la contrastación entre elementos materiales (formas espaciales) y no materiales (sueños, anhelos, sensaciones, miedos, entre otros). La exposición de los resultados se organiza en tres partes: las formas espaciales, las comparaciones, $y$ los sentidos. Se presentan citas textuales que refuerzan el análisis, al respecto se deja constancia que los verdaderos nombres de los entrevistados han sido cambiados a fin de resguardar su privacidad.

\section{La materialidad de las formas}

El significado del espacio no tiene existencia propia, está articulado con la materialidad, las biografías, las prácticas cotidianas y los lazos sociales. En la conformación del espacio geográfico es fundamental el conjunto de objetos y de acciones; porque a través de éstas se crean y recrean formas y sentidos. En el proceso de subjetivación el territorio deviene en lugar o espacio vivido. Los sentidos tienen una dinámica importante, en cambio, los recintos materiales tienden a perdurar en el tiempo, que cambia es su contenido, sea su función, significado o ambos (Santos, 2000).

Se exponen (Cuadro 1) las formas, los objetos, detectadas en los relatos e identificadas por 
la observación directa. Es preciso destacar que algunas formas fueron nombradas pero no existen. Son las reclamadas por los vecinos, como la red de agua potable y la de gas natural.

\begin{tabular}{|c|c|}
\hline \multicolumn{2}{|l|}{ Cuadro 1. Las formas del territorio } \\
\hline Identificadas en las entrevistas & Identificadas por la observación directa \\
\hline $\begin{array}{l}\text { Calles de tierra o granza, deterioradas, } \\
\text { plazas }\end{array}$ & $\begin{array}{l}\text { Calles cubiertas con pasto, calles } \\
\text { cerradas, puentes }\end{array}$ \\
\hline \multicolumn{2}{|l|}{ Sistema de transporte } \\
\hline Comercios, alojamientos, balnearios & $\begin{array}{l}\text { Parque recreativo sobre arroyo } \\
\text { Chapadmalal, Camping del EMDER, } \\
\text { Gimnasio Polideportivo, Museo Eva } \\
\text { Perón, Estafeta Postal, Rancho Móvil de } \\
\text { la Costa }\end{array}$ \\
\hline $\begin{array}{l}\text { Bosque, mar, playa, aves, vacas, } \\
\text { caballos, liebres, gallinas, flores. Zonas } \\
\text { inundables }\end{array}$ & Arroyos, lomas \\
\hline $\begin{array}{l}\text { Instituciones: sala de emergencias } \\
\text { médicas, escuelas, asociaciones de } \\
\text { fomento, club, Colonias, subdelegación } \\
\text { municipal, estación experimental de la } \\
\text { universidad, capillas, destacamento } \\
\text { policial }\end{array}$ & $\begin{array}{l}\text { Otras instituciones: Jardín de infantes, } \\
\text { bomberos }\end{array}$ \\
\hline Pocas casas & $\begin{array}{l}\text { Trama urbana abierta, extensión, límites } \\
\text { difusos, elevado número de lotes baldíos, } \\
\text { barrio privado }\end{array}$ \\
\hline Quintas & $\begin{array}{l}\text { Unidades de producción agropecuaria, } \\
\text { casas con molinos de viento y tranqueras, } \\
\text { colmenas, alambrados }\end{array}$ \\
\hline ersonal sobre $\mathrm{d}$ & primarios \\
\hline
\end{tabular}

Como se verá estos y otros objetos (de las ciudades, del entorno) están presentes en los contraste espacio-temporales y son referencia ineludible en la construcción de sentidos. Se puede relacionar con la concepción de lugar de (Agnew, 1987). Ese espacio, además de la carga emotiva atribuida por quienes lo construyen, forma parte de un todo más amplio, la constitución de los lugares se relaciona con procesos definidos por un adentro y un afuera.

\section{Las comparaciones}

Las historias de los sujetos se sitúan espacio-temporalmente y desde el presente se elaboran las narrativas espaciales, con comparaciones que contribuyen a identificar, en las lecturas del espacio, los sentidos que se le atribuyen. En los discursos se visualizan dos tipos de cotejos, los espaciales y los temporales, pero en las dos situaciones hay combinaciones entre ambas variables. 


\section{Contrastes espaciales}

Según de Certeau, “...el caminante constituye, con relación a su posición, un cerca y un lejos, un aquí y un allá" (2000, p. 111). De modo que en este conjunto son centrales los adverbios de lugar: allá, ahí, acá, alusiones inherentes a los propios desplazamientos que indican un proceso de apropiación y distinción del territorio. La marca dejada a través de los vocablos instala una articulación conjuntiva y disyuntiva de sitios (de Certeau, 2000). Dentro de las designaciones afectadas por el allá/ ahí, se encuentran dos escalas espaciales como son otra ciudad, otro barrio. Algunas veces el allá constituye un pretérito lejano, otras un pasado bastante reciente y por último una situación contemporánea, referida a un allá que es parte del espacio de vida actual.

Los allá distantes en el tiempo responden a lugares donde alguna vez se residió, pero no a las localizaciones desde donde se inició la migración o movilidad residencial. Son referencia ineludible en algunas entrevistas y coadyuvan a producir los sentidos de lugar e inclusive a fomentar la adaptación o el arraigo.

"Mi vida diaria es tranquila, no hay nada. Pero en Saladillo también vivía alejada de la ciudad y me acostumbré a la soledad. Hago las tareas de la casa y no mucho más. Acá es tranquilo" (mujer", 40 años).

Algunos sujetos no problematizan sobre el allá que se dejó y ponen una nota nostálgica por el lugar resignado. El allá o ahí contemporáneo, más o menos cercano en el tiempo, señala la proximidad de familiares y refiere a otros barrios de Chapadmalal, e inclusive de Mar del Plata o Miramar, donde se tienen vínculos más estrechos o profundos que los de simple vecindad.

"Tengo familia en la Estafeta, Los Lobos, en Miramar, en Mar del Plata, todas tías mías. Después el hermano de mi marido vive ahí en la esquina, cruzás la calle, en la otra manzana, justo la que está arriba, ahí. Él compró primero pero nosotros vinimos primero, ellos hacen dos años que están ahí..." (mujer ${ }^{10}, 49$ años).

"La más grande [su hija] se quiere ir a Miramar porque acá está lejos de sus amigos y no puede salir... tampoco puede invitar a nadie porque a todos les queda lejos, incómodo. A mí también me gusta Miramar y acá me gusta, pero me gustaría más ir a Santa Isabel donde está toda mi familia [hermana, madre, primos]" (mujer, 40 años).

\footnotetext{
${ }^{9}$ Lugar de residencia anterior: Ramos Mejía, Partido de La Matanza, provincia de Buenos Aires. Nació en esa localidad y residió en ella, con interrupciones, hasta el año 2008. Pertenece a un hogar con un buen nivel de ingresos, según ella misma declara. Su nivel educativo es secundario incompleto y es ama de casa. Su marido trabaja como contratista de construcción y en tareas de mantenimiento general de viviendas. Sus dos hijas asisten a una escuela privada en Miramar. No son propietarios de la vivienda donde residen, sino que la cuidan. Pero tienen una vivienda propia y un local comercial en el barrio Santa Isabel, ambos aún sin ocupar.

${ }^{10}$ Lugar de residencia anterior: San Eduardo de Chapadmalal. Es nacida en la ciudad de Lobería, cabecera del Partido homónimo, provincia de Buenos Aires, llegó a Chapadmalal a los 20 años. Su nivel educativo es secundario incompleto y es ama de casa, aunque en verano trabaja en las Colonias turísticas. Su marido es empleado estatal en las Colonias Turísticas. Son propietarios de su vivienda, tienen un automóvil nuevo y hacen viajes anuales a distintos lugares del país. Su hija asiste a una escuela privada en Miramar.
} 
Los restantes allá mencionados son parte de los espacios de vida cotidianos y adquieren significado en la medida que los sujetos los conocen, recorren y apropian. Para algunos el allá es obligado, para otros anhelado o casi inalcanzable, debido a limitantes como la distancia, los déficits del sistema de transporte y el costo monetario de los traslados. Mar del Plata y Miramar son los principales allá coetáneos, visualizados como puntos de inflexión en la rutina por sus ofertas de recreación, gastronomía y compras. Pero también por sus diferencias respecto de Chapadmalal debido a la mayor densidad de población, los ruidos, los miedos que generan.

"Como mi mujer va a Mar del Plata trae de los [supermercados] chinos. Tratamos de traer todo de Mar del Plata. Ya nos gusta cada vez menos ir a Mar del Plata... De Miramar no quiero saber nada. Allá tuve un tiempo muy malo" (varón ${ }^{11}, 48$ años).

"En Mar del Plata y en Miramar me siento bárbara, me gusta ver gente, el bullicio, acá no hay nadie, acá disfrutás de la soledad. Cuando necesito ver gente voy a Mar del Plata o a Miramar" (mujer, 40 años).

Los entrevistados destacan, casi sin excepción, la fortaleza en los vínculos entre convecinos, lo que constituye otro punto de partida en la elaboración de un nosotros (los habitantes de Chapadmalal) opuesto a los otros (los habitantes de las ciudades). Sin embargo, también se indica que a muchos no les interesa involucrarse, resaltan cierta ausencia de compromiso y participación por el bien común.

En base a estos primeros indicios se puede indicar que en Chapadmalal se encuentran como particularidades esenciales: tranquilidad y paz, silencio, soledad, falta de servicios, relativa seguridad, mayor libertad en algunas instancias de la vida diaria, considerable distancia a las ciudades más importantes, contacto con la naturaleza, baja densidad de población y viviendas. Todos estos rasgos van ayudando a definir un acá peculiar que confronta siempre con los allá previamente vividos, o que aún están siendo vividos como parte del espacio de vida presente.

\section{Comparaciones temporales}

Las evocaciones de los sujetos aluden a diversas temporalidades en las cuales los hechos se reviven en situaciones donde es primordial el juego entre la memoria y el olvido (Lindón, 2008), o bien lo que se teme recordar o poner en palabras.

Los contrapuntos temporales se evidencian en los adverbios de tiempo antes y ahora. Se advierte la existencia de un antes lejano y otro más próximo que marca el quiebre entre dos momentos de la vida. En el caso de los recién llegados se nota el tránsito por un camino de adaptación. Así, para algunos el antes es el período de arribo a Chapadmalal, tiempo de sentirse ajenos al lugar por carecer de historia y conocimientos que fueran de utilidad para la nueva vida (Santos, 2000).

\footnotetext{
11 Lugar de residencia anterior: Barrio Las Dalias, Mar del Plata. Es nacido en Quilmes, provincia de Buenos Aires. Llegó a Mar del Plata hace dieciocho años. El entrevistado se desempeña en la policía bonaerense y su mujer es empleada doméstica. Tienen un nivel de ingresos bajo, un automóvil roto y la imposibilidad económica de repararlo. Son propietarios de la vivienda y su hija asiste a una escuela de gestión pública en San Eduardo de Chapadmalal.
} 
"Cuando llegamos tuve miedo, en Saladillo tuve auto, me manejaba sola. Acá llegamos con ahorros, pero sin auto, sin trabajo. El tema era pensar cómo iba a manejarme, estando lejos de todo y sin vehículo y sabiendo que la movilidad no es continua. Después me fui adaptando y organizando. Pero te limita estar acá, tiene sus cosas buenas y otras no tanto" (mujer, 40 años).

"Cinco años antes de venirnos yo ya me quería ir a algún lado, mi marido no, a él le costó y recién hace un año medio mi marido se convenció. Pero yo me sentía ahogada en la casa, por el sistema había cambiado todo, los vecinos viejos no estaban, me quería venir para estar en paz" (mujer ${ }^{12}, 68$ años).

El antes, además, se usa para comparar la situación de la localidad o del barrio en relación con el pasado. En numerosas ocasiones lo temporal se define a través del acá, es decir, la localización en el territorio.

"Lo que pasa con todo esto es que no hay arena, acá [en la Estafeta] cuando yo era chico la playa era de doscientos por seiscientos metros. Ahora se está explotando más el sur, se está construyendo más" (varón ${ }^{13}, 39$ años).

“...aparte ahora hay más gente, antes cuando recién vinimos acá éramos nosotros solos y cuando él trabajaba de noche estábamos solas en cuatro o cinco cuadras" (mujer, 49 años).

Se nota la influencia de la temporalidad en la elaboración de los antagonismos entre lugares, lo que permite el surgimiento de un acá-ahora que confronta con otras situaciones, interactuando con las emociones, las historias personales, las vivencias, para aportar a la construcción de sentidos sobre Chapadmalal y otros lugares visitados con cierta asiduidad.

\section{Los sentidos}

En Chapadmalal la construcción de la trama de significados se realiza en torno a un eje material principal que se puede denominar "extensión natural y vacía", cualidad que propicia los cuatro grandes significados divisados: alejamiento; ideal; social y pertenencia.

\section{Sentido de alejamiento}

Residir en un poblado pequeño y alejado de las ciudades aparece como la realización de un ideal, aunque con claroscuros. La periferia se caracteriza por un vacío de materialidad en el cual la

\footnotetext{
${ }_{12}$ Lugar de residencia anterior: San Eduardo de Chapadmalal. Hasta su llegada a la zona vivió siempre en Ramos Mejía, Partido de La Matanza, provincia de Buenos Aires. Nació en Ciudadela, Partido de Tres de Febrero, provincia de Buenos Aires. La entrevistada y su cónyuge son jubilados y además obtienen ingresos a través de tareas de jardinería. Son propietarios de la vivienda y por el estado en que esta se encuentra y las actividades que realizan (teatro, restaurantes, viajes) es posible inferir un nivel de ingresos medio-alto. Además poseen un automóvil.

${ }^{13}$ Es nacido y criado en Chapadmalal. Ha emigrado temporalmente a otras pequeñas ciudades del país y también del extranjero (Italia, Gran Bretaña y Costa Rica). Se mantiene económicamente con trabajos de pintura y hasta el verano $2009-2010$ dirigió una escuela de surf que brindaba clases gratuitas a niños y adolescentes de la zona y que se sustentaba con el cobro de clases a turistas. Es propietario de una vivienda que alquila durante las temporadas, posee una moto y realiza una vida muy austera.
} 
lejanía, absoluta o relativa, sobresale la definición de las carencias (Lindón, 2006). Así, el significado se construye mediante la evaluación de oportunidades de acceso a bienes y servicios, pero también respecto de lo que no se posee y de lo que no se puede hacer (Butz y Eyles, 1997).

En este "estar lejos", no todo es negativo. El alejamiento se combina con la función turísticoresidencial de Chapadmalal, delineando una oferta laboral que oscila entre la estabilidad y la formalidad, la inestabilidad y la informalidad. Por ende, estar en Chapadmalal significa para algunos una oportunidad laboral y de cierto progreso económico.

“... cuando llegamos mi papá, que trabajaba de parquero, le dejó todos los clientes a mi marido y así empezó. Ahora no hace nada de parques... hace de albañil, electricista, de todo..también está levantando casas, siempre más y más trabajo, por suerte" (mujer, 40 años).

“...en el lugar en que uno trabajaba para vivir el día... En cambio acá ... uno pudo tener su casa, su auto, mi hija va a un colegio que lo podés pagar y que pueda estudiar ella ¿no?..." (mujer, 49 años).

Acerca del servicio de transporte se hace una valoración intermedia que no ayuda a reducir la sensación de lejanía. A los barrios de Chapadmalal llegan dos empresas de transporte público. El 221 (Rápido del Sur) y el $511 \mathrm{CH}$ (Peralta Ramos), el primero tiene una frecuencia de cuarenta o treinta minutos, según el momento del día y conecta a todas las localidades de la costa desde Miramar hasta Santa Clara del Mar.

La Empresa Peralta Ramos tiene cobertura local. En el momento de realización de las entrevistas ofrecía tres servicios diarios ${ }^{14}$, de modo que a la distancia se suman el tiempo de viaje, el elevado costo y la muy escasa frecuencia.

"...El servicio del colectivo es bueno, no me puedo quejar. El tema es el tiempo, es más esporádico que en Buenos Aires donde cada minuto tenés un colectivo. Acá tenés uno cada media hora y si lo perdés tenés que esperar..." (mujer, 40 años).

Aunque los estudiantes viajan gratis (enseñanza primaria) o con descuento (enseñanza secundaria), en el caso de los más pequeños la situación se hace engorrosa ya que suelen ir acompañados por un adulto que sí abona el pasaje. Se eligen entonces formas alternativas para recorrer la localidad, como el uso de las bicicletas, motos o la realización de caminatas.

"Hacemos todo caminando, camino unas 300 cuadras por semana para llevarla a ella al colegio, también la voy a buscar. A veces uso la bicicleta. Pero el auto lo tengo roto y el colectivo es muy caro" (varón, 48 años).

Otra contrariedad es que los colectivos no ingresan a los barrios y los pobladores deben acercarse a la ruta, lo que atenta contra la movilidad diaria por la distancia que algunos deben

\footnotetext{
${ }^{14}$ Según se pudo establecer, mediante entrevista con uno de los propietarios de la Empresa Peralta Ramos (9 de enero de 2011), la baja frecuencia se debe a un problema de rentabilidad. Este informante alegó que el servicio da pérdida porque "los colectivos van y vuelven vacíos...". Las demandas de los pobladores han motivado que desde agosto de 2012 la frecuencia diaria se incremente a ocho (8) servicios, con la extensión hasta el arroyo Las Brusquitas, en el límite con el partido de General Alvarado. Cfr. http://www. diarioelatlantico.com/diario/2012/08/08/45116-la-511-amplia-recorrido.html
} 
recorrer. Por tanto se fomenta la sensación de confinamiento, de falta de libertad para movilizarse.

Chapadmalal ofrece servicios educativos y sanitarios, los que fueron reconocidos por los entrevistados destacando la calidad de sus tareas. En cuanto al servicio educativo, hay dos jardines de infantes, dos escuelas primarias y una secundaria. Pero también es preciso resaltar que algunas familias prefieren enviar a sus hijos a escuelas privadas en la ciudad de Miramar. Acerca de la unidad sanitaria, se recurre a ella sobre todo en casos de emergencia.

En los barrios hay locales comerciales que sirven para satisfacer demandas cotidianas de la población estable. Pese esta posibilidad, hay familias que eligen comprar en Mar del Plata o Miramar, sea porque en las ciudades los precios son inferiores, porque hay más variedad de marcas y productos o porque pueden utilizar medios de pago como tarjetas de crédito o débito.

Las colonias turísticas actúan como eje de la vida de muchos habitantes que trabajan en ellas o se emplean en rubros vinculados a su desempeño: restaurantes, comercios, recreación. A este complejo se suman los balnearios, hoteles, hosterías, posadas, cabañas y spa. Todas estas formas constituyen, los fines de semana largos y en tiempo de vacaciones, fuentes de empleo.

Los sujetos relacionan algunas carencias directamente con la distancia respecto de Mar del Plata. En tal sentido, los pobladores demandan la instalación de redes de servicios públicos de agua y gas, además, afirman sentirse abandonados por la inacción del municipio y de las asociaciones de fomento. Chapadmalal depende de la Delegación Municipal del Puerto ${ }^{15}$ y hay propuestas de los vecinos en torno a la creación de una delegación propia, para contar con mayores recursos y reducir la distancia con las autoridades municipales. Pero hasta el momento, sólo se ha logrado la instalación de una Sub-delegación donde se hace el cobro de impuestos municipales.

Los vecinos se sienten relegados desde el municipio, en algunos casos se insinúa que la localidad es "tierra de nadie" o quizá, tan solo, tierra de los que tienen poder económico y político para transformar el territorio en función de intereses cortoplacistas. Frente a la municipalidad que olvida, muchos esperan que las sociedades de fomento cumplan con algunas funciones. Pero los vecinos entrevistados coinciden en que esas entidades no realizan tareas para mantener las calles de los barrios, limpiar terrenos y congregar demandas, además permanecen sin un horario de atención fijo.

Sin embargo, es importante mencionar que algunos sujetos advierten la apatía propia y ajena, la no participación, hecho que configura un campo favorable para la concreción de proyectos que no contemplan los intereses de la mayoría de los habitantes. Se combinan ambas situaciones: inacción institucional y relativa falta de participación o compromiso y no se generan respuestas a las demandas que se hacen de manera individual.

Para los residentes en Chapadmalal, su localización, el aislamiento relativo y la inaccesibilidad pueden ser una barrera para obtener bienes y oportunidades (Butz y Eyles, 1997), poniendo algunas sombras sobre la significación de la localidad como lugar ideal.

\footnotetext{
${ }^{15}$ En General Pueyrredon la división administrativa tiene como referentes a la municipalidad, situada en el microcentro de Mar del Plata, y a las delegaciones municipales que abarcan sectores extraejidales y rurales. Las delegaciones surgieron para la desconcentración de tareas debido a la amplitud territorial del distrito y la complejidad de algunas áreas como el Puerto o la ciudad de Batán. La delegación Puerto (desde la Av. Juan B. Justo hasta el límite con General Alvarado) atiende a la zona portuaria de la ciudad y, a la vez, una porción del territorio rural y localidades como Chapadmalal. En cada delegación los pobladores pueden resolver trámites como pago de tasas e impuestos, gestión de registros de conducir, habilitación y control de comercios, industrias y vehículos de carga o transporte, solicitud de permisos para ventas, publicidad en la vía pública o espectáculos. Asimismo, en estas subsedes municipales, el delegado recibe propuestas de conservación y mejora para su zona. Aunque en 1973 fue creada la Delegación de Santa Isabel (Chapadmalal), su falta de funcionamiento perjudica a los vecinos de la zona sur en general, especialmente, por la lejanía respecto del Puerto y del microcentro de Mar del Plata.
} 


\section{Sentido de lugar ideal}

En la definición de este sentido confluyen el sentirse en contacto con la naturaleza, tener libertad respecto de los vecinos, la seguridad, la tranquilidad.

Para los residentes de Chapadmalal este territorio es natural, ya sea porque posee características que acuerdan con su idea de naturaleza o por el contraste con la artificialidad propia de las ciudades ${ }^{16}$. Claro que muchas de las formas del paisaje contribuyen a delinear una noción de naturaleza atractiva y opuesta a los restantes lugares que conforman los espacios de vida.

Sentirse en contacto con la naturaleza es una expresión que aparece -más o menos palabra por palabra- en todos los discursos. La baja densidad de ocupación y de habitantes es visible, y es otro atributo contribuyente a creer que se está en el campo, cerca de la naturaleza donde se disfrutan, pero también se padecen, la soledad y el silencio. Algunos indican que con los años ha aumentado el número de viviendas y personas, otros sostienen, en cambio que la cantidad de habitantes no se ha incrementado demasiado por la dureza de la vida, las carencias, la lejanía.

"La tierra, ver animales sueltos, me hace sentir cerca de la naturaleza, a mi marido le gusta cosechar y sembrar, hizo quinta... A mí no me interesa, no sé nada, pero me gusta ver que mis hijas disfrutan de eso" (mujer, 40 años)

"Acá todo me hace sentir cerca de la naturaleza. Me gusta caminar, el pasto, las flores ¿viste las margaritas que hay?, el mar..." (mujer, 68 años)

La baja densidad de ocupación y la presencia de lotes vacantes; la trama abierta; los límites difusos a veces permeados por la actividad agropecuaria; el bosque, el mar y los arroyos. La presencia de casas bajas, terrenos más o menos amplios, molinos de viento, tranqueras, pequeñas quintas. Estos conjuntos de formas se suman a ideales, experiencias pasadas, lugares de la infancia, y juntos se articulan en la formación del sentido de naturaleza donde es importante la referencia al campo. Todo esto se agrega a los fragmentos de vida rural ubicados en torno al poblado y contribuye a delinear el aire campestre y natural que sus residentes observan y aprecian.

"Es una linda vida para ella [su hija], hay que cuidarla, acá andan las liebres sueltas, los pájaros. Yo amo a los animales ..." (varón, 48 años).

“...me gustó, me da mucha paz... Acá se lucha también, pero hay tranquilidad. Me harté, me saturé. Yo nunca quise vivir en el campo..." (mujer, 68 años).

“...soy tercera generación, este es mi lugar, después tengo otro en Costa Rica ${ }^{17}$, es pequeño, como acá, campestre, aunque cada vez es menos campestre" (varón, 39 años).

\footnotetext{
${ }^{16}$ Respecto de la pretensión de naturaleza, el tema se ha estudiado para las distintas localidades del Partido de General Pueyrredon en su conjunto, con similares resultados. (Mikkelsen y Ares, 2009).

${ }^{17}$ El entrevistado refiere a la República de Costa Rica.
} 
La naturaleza, representada también por la topografía ondulada, a veces puede ser hostil para los habitantes de Chapadmalal. Hay áreas que se anegan fácilmente lo cual dificulta la circulación, en especial de mujeres y niños. Otra cuestión se relaciona con el clima y con la crudeza de los inviernos, que parece mayor a la padecida en otros ámbitos por la inexistencia de gas de red, lo que determina elevados gastos en gas envasado o leña.

"Chapadmalal se hace grande en casas de verano, en cabañas. Pero la gente de siempre solo es un poquito más. Acá te frena mucho el problema del gas...Cuando pongan el gas va a cambiar" (varón, 39 años).

"Acá salgo menos, tengo que caminar hasta la ruta para tomar el colectivo.... Tenés que tener un vehículo sí o sí, eso es lo que te complica, estoy más encerrada, allá tenía más libertad. Antes de que naciera el bebé si estaba lindo nos íbamos con la más chica a pasear o a Miramar..."(mujer, 40 años).

La lejanía es un factor que ayuda a sentirse en la naturaleza pero, al mismo tiempo, da lugar a cierto confinamiento territorial. Se habla entonces de la "falta de libertad" para movilizarse según los deseos o necesidades, de límites impuestos por la distancia, el transporte público y el desafío de llegar hasta la ruta.

Por otra parte, la extensión y la baja ocupación del terreno propician la sensación de libertad respecto de los vecinos.

“"... en la ciudad estás muy expuesta y acá tenés libertad para vivir como querés, sin que el vecino te escuche. De acá lo que más me gusta es la paz, la libertad, que los chicos salgan tranquilos. Lo que no me gusta es tanto silencio" (mujer, 40 años).

Para algunos ir a Miramar o a Mar del Plata, ocasiona cierto agobio, molestias, cansancio. El contraste es abrumador y Chapadmalal se califica, una y otra vez, como un lugar natural.

“...Voy a Mar del Plata y me quiero volver porque no es mi entorno, pero no pienso que es una ciudad de mierda, pasa que no es mi lugar. Yo creo mucho en lo natural” (varón, 39 años).

"No me gusta quedarme en Mar del Plata, tomamos un café o caminamos por la costanera y volvemos, me descompongo, me volví una vieja campera. Miramar un rato pero no me gusta estar mucho...Pero es muy parecida a Ramos [Mejía], una casa tras otra, cuando veo cemento me siento ahogada" (mujer, 68 años).

La exaltación de lo natural exhibe una arista problemática para los que ven que se hace un abuso de sus elementos, la mayor parte por la actividad turística. Para algunos es imperioso preservar y cuidar la naturaleza, patrimonio de todos y no sólo de quienes tienen poder económico.

La sensación de seguridad se construye, en principio, por la confrontación con lo vivido y con lo que se transita a diario. Las personas reconocen sentirse inseguras, aterrorizadas, alertas, en 
ciudades como Mar del Plata o en aquellas pertenecientes al Área Metropolitana de Buenos Aires. No sucede lo mismo con Miramar.

"Acá me siento segura, en Miramar también pero en Mar del Plata no, siento inseguridad, estoy alerta, me pasa como en Buenos Aires. Pero no me da miedo..." (mujer, 40 años).

“...el barrio ahora está tranquilo. A Mar del Plata no vamos mucho, pero cuando vas sabés que tenés que andar con cuidado" (mujer, 49 años).

La definición de seguridad en Chapadmalal puede fluctuar según el tiempo de residencia. Los habitantes más antiguos, narran una seguridad relativa y reconocen cambios en los últimos años, evidenciados en el incremento de los delitos aún en residencias de pobladores estables ${ }^{18}$.

"Acá hay algunos problemas de seguridad, a mi no me pasó nada...Me siento segura [tiene toda la casa abierta]. En Mar del Plata ...nunca tuvimos problemas y vamos tranquilos a todos lados. En Miramar igual, voy a los mismos lugares y no hay problema" (mujer, 68 años).

"... asaltan casas cuando saben que hay mucha gente, un asado, un festejo. El año pasado hubo dos casos, los encapuchan a todos, secuestran al dueño y lo llevan a sacar plata de los cajeros. ¿Cómo nadie se da cuenta?..." (varón, 39 años).

Predomina, no obstante, la sensación de que nada malo puede ocurrir: la presencia de tranqueras, portones, ventanas, todo abierto, casi sin rejas, hace que cualquier visitante acuerde con la sensación de seguridad, expuesta en muchos relatos.

Estar seguros conlleva tranquilidad, paz, sensación de bienestar. Como se expuso, aunque la mayoría se siente segura, hay personas que admiten una progresiva pérdida de esa cualidad.

“Me asusto más cuando pasa la policía que cuando no pasa, pero... ahora dentro de todo está tranquilo, pero hace unos años atrás no, andaba más la policía pero también uno sabía que cuidaba a los que venían y abrían tu casa. ¿Pero que le vas a hacer?... Acá todavía respiramos aire puro, es tranquilo, hermoso" (mujer, 49 años).

La tranquilidad también se conecta con los escasos ruidos, la baja densidad de población, el ritmo sosegado de vida. Quien reside en Chapadmalal, enuncian los entrevistados, ya no corre, tiene menos presiones, procura trabajar y vivir con menos. El hecho de tener menor consumo también se asocia con la obtención de tranquilidad. Por otra parte, se resaltan el estar cerca de la familia y tener la posibilidad de criar a los hijos con mayor libertad, como valores que contribuyen a estar en paz.

Las restantes localizaciones del espacio de vida no gozan por igual de este sentido, sino que provocan distintos grados de intranquilidad relacionados con la inseguridad, el bullicio.

\footnotetext{
$\overline{18}$ Cfr. las siguientes notas periodísticas. "Vecinos de Playa Chapadmalal preocupados por ola de inseguridad", 15 de diciembre de 2009. Diario El Atlántico, Mar del Plata y "Vecinos de la zona sur aseguran que no circulan móviles policiales", 17 de diciembre de 2009. Diario El Atlántico, Mar del Plata.
} 
"Miramar es bien pueblo, gente pueblerina, te brindan su confianza, la gente se toma tiempo para la siesta, a las 12 se cierra y hasta las 16.3 no pasa nada, igual que en Saladillo. Mar del Plata es una ciudad y a la hora que vas tenés todo" (mujer, 40 años).

Con respecto a Mar del Plata, y también acerca de las localidades de residencia anterior, se elabora un sentido de peligro, sustentado en hechos conocidos a través de vivencias o mediante los discursos periodísticos. De modo que las personas reconocen ir atentas a lo que sucede, alertas y dispuestas a evitar lugares considerados peligrosos, como las villas, las plazas en horarios nocturnos o barrios que no se conocen.

El mundo más allá de la muerte se representa, en distintas cosmovisiones, semejante a los lugares terrenales, aunque siempre excluyendo los aspectos desagradables y penosos propios del mundo de los vivos (Tuan, 2004). De este modo es posible comprender que para algunas personas Chapadmalal sea un paraíso, es decir, un espacio sin los peores defectos de las urbes y con virtudes que parecen haber quedado idealizadas para el mundo rural.

"Chapadmalal es el paraíso [se le llenan los ojos de lágrimas], pero tengo dos hijos allá [partido de Merlo, AMBA], pero ya van a venir, parece que se van a venir, es un sueño, sería ideal [más lágrimas, pausa]" (mujer, 68 años).

Se percibe el uso del término en un sentido metafórico, poético, ya que sus pequeños paraísos no están ajenos a las dificultades admitidas, aunque minimizadas.

"Esto es un paraíso, hace un año y pico [abril de 2009] que estamos acá, mi señora, mi nena y yo... El verano es hermoso, el invierno también, me ha tocado mojarme para ir a tomar el colectivo pero cuando llegás a la ruta y ves el mar no te importa nada ¿cuánto tendría que pagar para disfrutar de esto?" (varón, 48 años).

\section{Sentido Social}

En su conformación es dominante la importancia de los lazos sociales y la interacción entre personas (Butz and Eyles, 1997). Las relaciones entre vecinos son un factor importante en la construcción de los espacios vividos, en tanto el uso cotidiano del espacio y las relaciones sociales que se gestan son precursores de los sentidos de pertenencia (Esquivel Hernández, 2006). La "buena" vecindad se expresa en acciones solidarias, en gestos y saludos. Los vecinos de Chapadmalal valoran mantener la distancia como forma de conservar su libertad respecto de las personas con quienes se comparte la localidad.

“...te conozcan o no te ayudan, te saludan, siempre se inicia una charla. Allá un vecino nuevo quizá nunca tenga una relación, hay una indiferencia total..." (mujer, 40 años).

“... entre los vecinos nos cuidamos, pero nada de estar todo el día en la casa de uno tomando mate, acá cada uno está en su mundo" (varón, 48 años). 
Por oposición, en las ciudades reinan la indiferencia, el anonimato, el mirar hacia otro lado, es decir, acciones que no ayudan a consolidar los lazos sociales. Además, la baja densidad de población, la libertad y la lejanía pueden conducir al desarrollo de cierta soledad, la que no siempre es sentida de modo positivo.

Un ámbito donde se desarrollan con fuerza las relaciones sociales y también las de poder, son las asociaciones vecinales o sociedades de fomento (AVF) de los distintos barrios. Los entrevistados acuerdan en decir que estas instituciones siempre están cerradas y resulta difícil plantear reclamos o ingresar y ser participantes activos.

De modo que en este punto es donde las relaciones de vecindad alabadas tienden a desmoronarse, ya que los integrantes de las AVF son convecinos de los entrevistados. Hay algunos sujetos que reconocen no participar o bien, estar cansados de luchar contra la corriente. Otros indican que los vecinalistas solo aparecen para pedir el pago de las cuotas, pero que nunca están disponibles para atender los reclamos.

La mención de buenas relaciones sociales entre vecinos aparece como una constante, sobre todo en los pobladores más nuevos. Los más experimentados, claro está, ya han descubierto las imperfecciones y las hacen notar en sus discursos. Se identifica la existencia de algunas fuentes de conflicto: diversas formas de maltrato a la naturaleza, no participación o participación que no considera al bien común.

“Acá está todo abandonado, los balnearios tiran las cloacas al arroyo ${ }^{19}$ [el Lobería], yo les digo que hay que pedirles que usen cisterna, pero no quieren gastar y el arroyo está contaminado... Yo me enojo porque vivo del turismo hace un montón de años" (varón, 39 años)

\section{Sentido de Pertenencia o arraigo}

En las ciencias sociales el concepto de pertenencia tiene una delimitación multidimensional, pero siempre con énfasis en la idea de membresía respecto de algo. Pertenecer también se asocia con la memoria, el conocimiento acumulado y las experiencias corporales de la vida cotidiana, es decir, "con experiencias pasadas y presentes y recuerdos y lazos, futuro vinculado a un lugar, que crecen con el tiempo (Fullilove, 1996; Crang, 1998)" (apud Fenster, 2004, p. 247).

Para quienes el arraigo y el sentido de pertenencia son muy fuertes, sobre todo porque se trata de personas que son tercera o inclusive cuarta generación en el poblado, no hay un allá relevante, un afuera de la localidad que los invite a salir, demorarse, e inclusive pensar en una emigración. Es en Chapadmalal donde han tejido la mayor parte de sus historias.

"Soy de acá, ese que está ahí [señala una fotografía antigua] era mi abuelo... tenía su chacra acá, en lo de Martínez de Hoz. Mi familia está acá desde 1913. Soy tercera generación, este es mi lugar... Odio que me hayan roto este lugar, yo conozco mucho, pude viajar. Pero este lugar es único y me lo están rompiendo todo" (varón, 39 años).

\footnotetext{
$\overline{19}$ Cfr. http://mardelplatasos.blogspot.com/2010 $06 \quad 01$ archive.html. El grupo tiene su base en Chapadmalal pero defiende todas las causas ambientales que ocurran en General Pueyrredon y apoyo y difusión de las causas relacionadas en el país y el mundo. Intereses: defensa de la Ordenanza Municipal 10011 donde se declara al Paseo Costanero sur como "Reserva Turístico Forestal" (del Faro a las Brusquitas), medio ambiente, problemas de salud por agroquímicos, contaminación en arroyos, entre otros.
} 
El hecho de ser "nacido y criado", o al menos criado, en Chapadmalal no es el único detonante en el arraigo. En la localidad las personas encuentran un espacio distinto al que dejaron, pero algunas tienen tal grado de apropiación que aparece el sentido de pertenencia, elaborado en el cotidiano, marcando la preferencia e inclusive hablando del fin de sus días en estas tierras.

"Yo soy aventurera, la monotonía no me gusta, me gusta agarrar la mochila y salir, pero ahora no, estoy bien acá, acá me voy a morir. Quiero esto, mis plantas, el mar" (mujer, 68 años).

"Esto es un paraíso...Yo soy de Buenos Aires, de Quilmes, hace 18 años que estoy acá...pero ya hice raíces y le dije a mis viejos que mis huesos se van a enterrar acá. Chapadmalal es mi lugar en el mundo, yo amo la naturaleza, es decir, el verde, el aire, el mar. Si esto lo tenés que pagar ¿cuánto te sale? ..." (varón, 48 años).

En la construcción de este sentido también participan las evocaciones de quienes hallan en Chapadmalal reminiscencias de su infancia en el campo o en pequeñas localidades de otras provincias. Recuerdos y sentidos se recrean en otros espacios físicos, en distintas coordenadas espacio-temporales, en procura de recuperar los lugares de felicidad. Se identifican en las narraciones, los procesos de resignificación del lugar a partir de recuerdos del pasado.

Los residentes que llevan en Chapadmalal varios años, ya conocen la historia o al menos parte de ella. De manera que tienen un punto de referencia, en ese pasado no tan lejano, para medir los cambios. Ante las transformaciones previamente comentadas, se pone de manifiesto una mayor fortaleza del sentido de arraigo para robustecer una posición que pueda afrontar, y confrontar, los cambios. Aquí se destacan, el fin de la tranquilidad por el arribo visible de nuevos pobladores "está viniendo todo el mundo", "están haciendo cabañas por todos lados", la contaminación y los manejos dudosos del ecosistema costero, y la decreciente seguridad personal.

"No me opongo al progreso, pero sí a que se estropeé todo. Se podría reforestar, usar una cisterna para las cloacas de los balnearios, cuidar la arena. El de Luna Roja puso dos cabañas arriba de un médano; los de $\mathrm{RCT}^{20}$ sacaron un médano para hacer un balneario, Arameo, al que no va nadie ¡es un fantasma! No tiene arena, no hay... La arena que saqués no vuelve" (varón, 39 años).

El sentirse parte de algo y constatar que se está entre iguales también es un elemento que ayuda a definir el arraigo a un lugar, como se vislumbra en los discursos, cuando se propone un "nosotros" identificable con claridad.

“...Lo que más aprecio es la paz del lugar, el amor a la naturaleza. La gente que tiene casa acá, jubilados en general, aprecian la paz, la buena vecindad" (mujer, 40 años).

"La gente que viene es muy tranquila, amable, no es distinta a nosotros. Somos todos muy tranquilos" (mujer, 68 años).

${ }^{20}$ Residencias Cooperativas de Turismo, centro vacacional con la modalidad tiempo compartido 
“...Que no venga más gente. Yo digo que el que viene acá que sea con buenos sentimientos, poder compartir los años de vida que me quedan bien" (varón, 48 años).

Pertenecer a Chapadmalal implica sentirse parte de algo distinto, aquí algunos vecinos son de toda la vida y otros no, pero ambos grupos coinciden en la necesidad de mantener las condiciones de la localidad a fin de que no pierda su esencia. Al mimo tiempo, se reconoce el deseo de residir allí de forma indefinida y trabajar en pos del bien común.

\section{Recomponer la trama}

Pensar en la trama de sentidos como el conjunto de hilos que se cruzan y enlazan con la urdimbre (las formas, las prácticas), formando una tela (el espacio vivido) es la metáfora necesaria para no desgajar la realidad. Por un lado, los sentidos no se escinden entre sí, ni tampoco de la realidad donde se constituyen. Por otro lado, la fuerza de las individualidades no queda descontextualizada de lo social, ni lo minimiza. El entramado constituye una muestra de los significados que dan forma al espacio vivido, producidos por los distintos modos de leer al espacio a través de las vivencias actuales y pretéritas, por formas de pensar, deseos, miedos, sentimientos positivos y negativos respecto de las localizaciones donde se transita y especialmente donde se permanece.

Laidentificación de sentidos presuponeun análisis minucioso delas narrativas, deconstruyéndolas para luego reconstruir la trama que los sujetos ponen en juego cuando reconocen a un lugar como propio, semantizándolo y usándolo de acuerdo con necesidades, contingencias y subjetividades. De esta manera Chapadmalal (Ver Cuadro 2), de acuerdo con la perspectiva de los entrevistados, se reconoce como lugar ideal donde se conjugan beneficios de la vida "en el campo" (tener huerta, estar cerca de la naturaleza, gozar del aire puro y la proximidad al mar, tener pocos vecinos, disfrutar de tranquilidad y seguridad) con relaciones sociales que se califican en general como buenas, privilegiando la solidaridad y afabilidad de los restantes pobladores. 


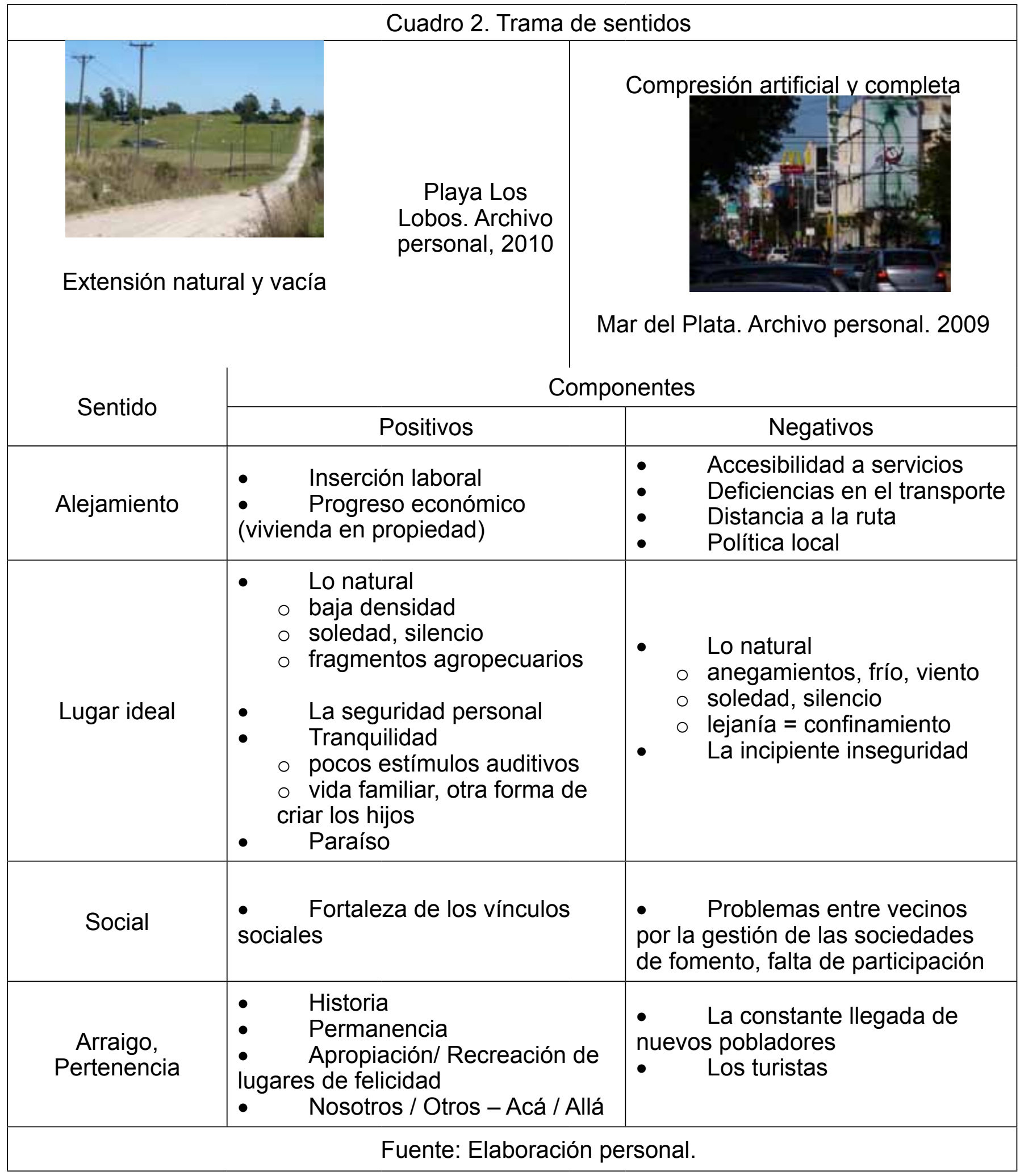

Además, la localidad es vivida como distante o alejada de todo, sentido favorecido por la baja densidad de población y las dificultades para trasladarse hasta Mar del Plata o Miramar. Se evidencia que el poblado es un lugar donde hay privaciones y servicios mínimos para la vida diaria. Todo junto, sumado al acervo de conocimiento de los sujetos, propicia el sentirse parte de un lugar distinto, gestándose el sentido de pertenencia o arraigo.

Los individuos entrevistados forman parte de una sociedad que en conjunto construye el territorio. Por tanto, se procuró que las individualidades no fueran separadas de su contexto social. Aquí también es destacable el enfoque de los espacios vividos ya que la relación subjetiva entre las 
personas y el territorio amerita ser indagada para comprender los usos y no-usos del territorio.

Se sostiene que los aportes de los sujetos son centrales para delinear políticas territoriales congruentes con los significados de los lugares, con las valoraciones enunciadas por los sujetoshabitantes. En este punto se reconoce, no obstante, que la trama de sentidos no es estática, puede modificarse a lo largo del tiempo, con lo cual es una guía para la gestión pública y el mayor acercamiento entre el poder político y los ciudadanos.

También se ha vislumbrado que el espacio vivido o lugar constituye un resquicio donde las alternativas potenciales (las búsquedas, los anhelos que movilizan el poblamiento) se convierten en formas concretas de vivir.

En resumen, a través de esta aproximación se observó cómo el recorrido por la subjetividad espacial complementa los conocimientos producidos con anterioridad y cómo la complejidad del territorio crece en la medida que se cree alcanzar sus secretos más recónditos.

\section{Referencias bibliográficas}

Agnew, J. (1987) Place And Politics: The geographical mediation on state and society, Boston: Allen And Unwin.

Álvarez, G. (2005, mayo). Geografía y discurso: lugar y segregación urbana en un barrio del Partido de General San Martín, provincia de Buenos Aires. Argentina. Documento presentado en: Taller Internacional: Desplazamientos, contactos, lugares. Ciudad Autónoma de Buenos Aires. Argentina.

Ares, S. y Mikkelsen, C. (2010) Dime donde vives y sabré porqué llegaste. Investigaciones Geográficas 72: 101-119. UNAM, Instituto de Geografía. México.

Ares, S., Mikkelsen, C. y Sabuda, F. (2011) Identificación de localidades en el Partido de General Pueyrredon a partir de la implementación de tecnologías de información geográfica (TIGs). Geograficando, 7, 7: 51-68. Universidad Nacional de La Plata.

Ares, S. (2008) Movilidad Territorial y Calidad de Vida en Chapadmalal, Partido de General Pueyrredon. [versión electrónica]. Hologramática, 8,1: 51-75 UNLZ. Recuperado el 25 de mayo de 2008 en http:// www.cienciared.com.ar/ra/doc.php?n=826.

Ares, S. (2010) Espacio de vida y movilidad territorial habitual en Chapadmalal (Buenos Aires, Argentina). [versión electrónica]. Cuadernos de Geografía, 19: 27-40. Facultad de Ciencias HumanasUniversidad Nacional de Colombia. Recuperado el 10 de diciembre de 2011 en http://www.revistas. unal.edu.co/index.php/rcg/article/viewFile/16840/17712

Berger, P. y Luckmann, T. (1998) La construcción social de la realidad. Buenos Aires: Amorrortu Editores. Primera edición 1968

Butz, D. \& Eyles, J. (1997) Reconceptualizing senses of place: social relations, ideology and ecology. Geografiska Annaler Series B, Human Geography, 79: 1-25.

Comerci, M. E. (2010) Territorialidades, espacios vividos y sentidos de lugar en tiempos de avance de la frontera productiva. Mundo Agrario, 11, 21. Centro de Estudios Histórico Rurales. Facultad de 
Humanidades y Ciencias de la Educación. Universidad Nacional de La Plata.

De Certeau, M. (2000) Invención de lo cotidiano. 1. Artes de hacer. México: Universidad Iberoamericana. Departamento de Historia.

Di Méo, G. (1999) Géographies tranquilles du quotidien. [versión electrónica]. Cahiers de Géographie du Québec, 43, 118: 75-93. Recuperado el 25 de mayo de 2008 en http://www.cgq.ulaval.ca/textes/ vol_43/articles43.html

Esquivel Hernández, M. T. (2006). Conformando un lugar: narrativas desde la periferia metropolitana. En Ramírez Kuri, P. y Aguilar Días, M. (coord) Pensar y habitar la ciudad. Afectividad, memoria y significado en el espacio urbano contemporáneo. UAM (México)-Barcelona: Anthropos. pp. 35-49.

Fenster, T. (2007) Gender and the City: the Different Formations of Belonging. In: Nelson, L. and Seager, J. (Eds.) A Companion to Feminist Geography. Oxford, UK: Blackwell Publishing Ltd. pp. 242-256.

Haesbaert, R. (2004) O mito da desterritorializaçao. Do "fim dos territórios" a multiterritorialidade. Rio de Janeiro: Bertrand Brasil.

Lindón, A. y Hiernaux, D. (Dir). (2011) Los giros de la geografía humana. Desafíos y horizontes. México: Anthropos.

Lindón, A. (2006) Del suburbio como paraíso a la espacialidad periférica del miedo. En Lindón, A.; Aguilar, M. y Hiernaux, D. (Coord) Lugares e imaginarios en la metrópolis. México-UAM: Anthropos. pp. 85-105.

Lindón, A. (2007a) Geografías de la vida cotidiana. En Hiernaux, D. y Lindón, A. (Dir). Tratado de Geografía Humana. México-UAM: Anthropos. pp. 356-400.

Lindón, A. (2007b). Los imaginarios urbanos y el constructivismo geográfico: los hologramas espaciales. Eure, 33, 99: 31-46.Santiago de Chile.

Lindón, A. (2008). De las geografías constructivistas a las narrativas de vida espaciales como metodologías geográficas cualitativas. ANPEGE, 4: 03-27.

Lucero, P. (2004) Población y poblamiento del Partido de General Pueyrredon. La combinación entre tiempo y espacio en la sociogeografía local. En Velázquez, G., Lucero, P. y Mantobani, J.M. (Autores y Ed.) Nuestra Geografía Local. Mar del Plata: GESPyT, UNMdP. pp. 37-76.

Mikkelsen, C. y Ares, S. (2009, marzo). "Regreso" a la naturaleza y movilidad espacial en localidades menores del Partido de General Pueyrredon (Buenos Aires). Documento presentado en: IV Congreso 
Argentino y Latinoamericano de Antropología Rural. Mar del Plata, Buenos Aires.

Nuñez, A. (2000) Morfología social de Mar del Plata (1874-1990). Tandil: Grafikart.

Reguillo, R. (2000) La clandestina centralidad de la vida cotidiana. En Lindón, A. (coord.) La vida cotidiana y su espacio-temporalidad. Barcelona: Anthropos. pp. 77-93.

Sagua, M. (2004) Dinámica sociodemográfica y ambiente al interior del Partido de General Pueyrredon. En Velázquez, G., Lucero, P. y Mantobani, J.M. (Autores y Ed.) Nuestra Geografía Local. Mar del Plata: GESPyT, UNMdP. pp. 129-165.

Santos, M. (2000) La naturaleza del Espacio. Técnica y Tiempo. Razón y Emoción. Barcelona: Editorial Ariel.

Sassone, S. (2002) Espacios de vida y espacios vividos. El caso de los inmigrantes bolivianos en el área metropolitana de Buenos Aires. [versión electrónica]. En Salman, T. and Zoomers, A. (eds) EI éxodo andino. La migración transnacional desde Bolivia, Ecuador y Perú. Cuadernos del CEDLA. Centre for Latin American Research and Documentation. Keizersgracht 397, 1016 EK Amsterdam. Recuperado en octubre de 2010 http://www.cedla.uva.nl pp.91-121.

Tuan, Y. (2004) Topofilia. Un estudio de las percepciones, actitudes y valores sobre el entorno (19 Edición en Español). Barcelona: Melusina. (Trabajo original publicado en 1974). 